\title{
Differential Effects of Acute Serotonin and Dopamine Depletion on Prepulse Inhibition and P50 Suppression Measures of Sensorimotor and Sensory Gating in Humans
}

\author{
Collette Mann', Rodney J Croft', ${ }^{1,3}$ Kirsty E Scholes², Alan Dunne ${ }^{3}$, Barry V O'Neill ${ }^{3}$, Sumie Leung ${ }^{3}$, \\ David Copolov', K Luan Phan ${ }^{1,4}$ and Pradeep J Nathan*, 1,5,6 \\ 'Behavioural Neuroscience Laboratory, School of Psychology, Psychiatry and Psychological Medicine, Monash University, Melbourne, VIC, Australia; \\ ${ }^{2}$ Centre for Clinical Research in Neuropsychiatry, School of Medicine and Pharmacology, University of Western Australia, Perth, WA, Australia; \\ ${ }^{3}$ Biological Psychiatry Research Unit, Brain Sciences Institute, Faculty of Life and Social Sciences, Swinburne University of Technology, Melbourne, \\ VIC, Australia; ${ }^{4}$ Clinical Neuroscience and Psychopharmacology Research Unit (CNPRU), Department of Psychiatry, University of Chicago, \\ Chicago, IL, USA; ${ }^{5}$ Department of Psychiatry, University of Cambridge, Cambridge, UK; ${ }^{6}$ Clinical Pharmacology and Experimental Medicine, \\ GlaxoSimthKline, Cambridge, UK
}

\begin{abstract}
Schizophrenia is associated with impairments of sensorimotor and sensory gating as measured by prepulse inhibition (PPI) of the acoustic startle response and P50 suppression of the auditory event-related potential respectively. While serotonin and dopamine play an important role in the pathophysiology and treatment of schizophrenia, their role in modulating PPI and P50 suppression in humans is yet to be fully clarified. To further explore the role of serotonin and dopamine in PPI and P50 suppression, we examined the effects of acute tryptophan depletion (to decrease serotonin) and acute tyrosine/phenylalanine depletion (to decrease dopamine) on PPI and P50 suppression in healthy human participants. In addition, we also examined for the first time, the effects of simultaneous serotonin and dopamine depletion (ie combined monoamine depletion) on PPI and P50 suppression. The study was a double-blind, placebo-controlled cross-over design in which 16 healthy male participants completed the PPI and P50 paradigms under four acute treatment conditions: (a) balanced/placebo control, (b) acute tryptophan depletion, (c) acute tyrosine/phenylalanine depletion, and (d) acute tyrosine/ phenylalanine/tryptophan depletion (combined monoamine depletion). Selective depletion of dopamine had no significant effect on either PPI or P50 suppression, whereas selective serotonin depletion significantly disrupted PPI, but not P50 suppression. Finally, the simultaneous depletion of both serotonin and dopamine resulted in significant reduction of both PPI and P50 suppression. We suggest these results can be explained by theories relating to optimal levels of monoaminergic neurotransmission and synergistic interactions between serotonergic and dopaminergic systems for normal 'gating' function. These findings suggest that a dysfunction in both serotonin and dopamine neurotransmission may, in part, be responsible for the gating deficits observed in schizophrenia, and their normalization following administration of atypical antipsychotic drugs.
\end{abstract}

Neuropsychopharmacology (2008) 33, 1653- 1666; doi:I0. I038/sj.npp. I 30I556; published online 26 September 2007

Keywords: sensory gating; PPI; P50 suppression; dopamine; serotonin; schizophrenia

\section{INTRODUCTION}

A disturbance in information processing has long been regarded as a significant feature of the deficits characteristic of schizophrenia (Braff, 1993; McGhie and Chapman, 1961). In particular, the filtering or 'gating' of sensory information is thought to be disrupted in schizophrenic patients, and this is hypothesized to lead to sensory flooding and

*Correspondence: Professor PJ Nathan, Brain Mapping Unit, Department of Psychiatry, University of Cambridge, Addenbrooke's Hospital, Hills Road, Cambridge CB2 2QQ, UK, Tel: + 6I 399053952 , Fax: + 613 99053948, E-mail: pradeep.nathan@med.monash.edu.au Received II April 2007; revised I 9 July 2007; accepted 3I July 2007 cognitive fragmentation (Braff and Geyer, 1990). Two psychophysiological measures of gating have been of particular interest to researchers in the study of schizophrenia, namely prepulse inhibition (PPI) of the acoustic startle response and P50 suppression of the auditory event-related potential (ERP).

The acoustic startle reflex is a defense response consisting of series of muscular contractions that can be elicited in response to a sudden loud stimulus with abrupt onsets (Landis and Hunt, 1939; Prosser and Hunter, 1936). PPI of the startle reflex refers to an attenuation of this startle reflex that occurs when the evoking stimulus is preceded by a non-startling 'prepulse' by approximately $30-500 \mathrm{~ms}$ (Graham, 1975; Hoffman and Fleshler, 1963; Ison et al, 
1973). In humans, the startle reflex is typically measured via the electrical activity of the orbicularis oculi muscle using electromyography (EMG) (Graham, 1975), and the PPI is typically calculated as a percentage score of the reduction in magnitude of this measure of the startle reflex, with maximal inhibition generally observed with 'lead intervals' of approximately $120 \mathrm{~ms}$ (Graham, 1975; Hoffman and Fleshler, 1963; Ison et al, 1973). It has now been well documented that patients with schizophrenia display a deficit in PPI (for a review see Cadenhead and Braff, 1999; Braff et al, 2001, 2007), which is interpreted as reflecting a failure of 'sensorimotor gating' (Braff and Geyer, 1990), and which may be normalized with the use of atypical antipsychotic drugs (Weike et al, 2000; Hamm et al, 2001; Kumari and Sharma, 2002; Kumari et al, 2007).

P50 is a positive deflection in the auditory ERP that occurs approximately $50 \mathrm{~ms}$ after the presentation of an auditory stimulus. In a double-click (or double-tone) paradigm, two clicks are presented $500 \mathrm{~ms}$ apart, and normal individuals show a reduced response to the second click (Click 2 or S2) relative to the amplitude of the first click (Click 1 or S1) (termed P50 suppression) with interstimulus intervals (ISIs) between 500 and $2000 \mathrm{~ms}$. Analogous to PPI, the second stimulus is 'gated' or inhibited by the initial stimulus. The P50 is measured via electroencephalography (EEG), where it is maximal at the vertex, and suppression is described as a ratio (ie Click 2 PSO amplitude/Click 1 P50 amplitude) or difference score (ie Click 2 P50 amplitude-Click 1 P50 amplitude). Normal control participants normally exhibit suppression in the range of $50-70 \%$ (Adler et al, 1999), while it has been demonstrated that patients with schizophrenia display significantly lower P50 suppression (Adler et al, 1982; Boutros et al, 1991; Light et al, 2000; Ward et al, 1996; Yee and White, 2001; Braff et al, 2007), which is interpreted as reflecting a deficit in 'sensory gating' (Adler et al, 1982). Analogous to the PPI findings, there is also some evidence that P50 suppression deficits in schizophrenia may be normalized with the use of atypical antipsychotic drugs (Light et al, 2000; Nagamoto et al, 1996, 1999; Adler et al, 2004; Becker et al, 2004).

Although PPI and P50 suppression are thought to reflect similar or related constructs, the actual relationship between the two is still unclear, with recent studies suggesting that these paradigms may be assessing different neural mechanisms (Brenner et al, 2004; Oranje et al, 2006). For example, it has been suggested that PPI and P50 suppression are related only insofar as hippocampal circuitry is involved in both processes (Swerdlow et al, 2000).

The neurochemical basis of schizophrenia has been linked to dysfunction in a number of neurotransmitter systems, including the glutamatergic, dopaminergic, and serotonergic systems (for reviews see Laruelle et al, 2003; Geyer et al, 2001; Dean, 2003). However, to date, the exact mechanisms of their role in gating dysfunctions in schizophrenia have not been determined. Animal studies have shown that sensorimotor gating, as measured by PPI, can be modulated by a number of neurotransmitter systems including dopaminergic, glutamatergic, serotonergic, GABAergic, and cholinergic systems (for a review see Geyer et al, 2001). However, these studies have been fairly inconsistent, both in terms of their findings and in the parameters used to measure gating (eg different prepulse intensities and prepulse to pulse intervals in PPI, lack of uniformity across laboratories in P50 peak detection, EEG processing, and filtering and differences in findings using different strains of animals) (Geyer et al, 2001). Pharmacological research on PPI and P50 suppression in humans is scarce, and discrepancies between animal and human studies on sensorimotor and sensory gating have also been documented, particularly for the serotonergic system (for a discussion see Hammer et al, 2007). Hence, it is critical that studies in humans are conducted to examine the neurochemistry of both sensorimotor and sensory gating.

Although it has been extensively hypothesized that serotonin and dopamine play an important role in the pathophysiology and treatment of Schizophrenia, their role in modulating PPI and P50 suppression in humans is yet to be fully clarified. Studies investigating the effects of serotonergic modulation on PPI in healthy humans have been inconclusive. Enhancing serotonin neurotransmission with MDMA (3,4-methylenedioxy- $N$-methylamphetamine or ecstasy), a presynaptic serotonin releaser (Liechti et al, 2001), and the 5- $\mathrm{HT}_{2 \mathrm{~A} / 1 \mathrm{~A}}$ agonist, psilocybin (GouzoulisMayfrank et al, 1998; Vollenweider et al, 1999), has been shown to increase PPI. However, the effects of psilocybin on PPI may be dependant on the ISI, with another study finding a decrease in PPI at ISIs of $30 \mathrm{~ms}$, no effects at ISIs of $60 \mathrm{~ms}$, and an increase in PPI at 120-2000 ms (Vollenweider et al, 2007). On the other hand, reducing serotonergic neurotransmission with ketanserin (a non-selective $5-\mathrm{HT}_{2}$ receptor antagonist) (Graham et al, 2002) or buspirone (a $5-\mathrm{HT}_{1 \mathrm{~A}}$ partial agonist acting presynaptically) (Gogos et al, 2006) has been found to reduce PPI. Nevertheless, other studies have found no effects on PPI following enhancement of central serotonin levels with the administration of serotonin reuptake inhibitors, fenfluramine (Abel et al, 2007), fluvoxamine (Phillips et al, 2000b), citalopram (Liechti et al, 2001), and escitalopram (Jensen et al, 2007). To our knowledge, the effects of serotonergic modulation on P50 suppression in healthy humans has only been investigated once, with findings showing a decrease in P50 suppression with the psychedelic plant ayahuasca, which contains many active constituents including $\mathrm{N}, \mathrm{N}$-dimethyltryptamine, a $5-\mathrm{HT}_{2 \mathrm{~A} / 2 \mathrm{C}}$ receptor agonist (Riba et al, 2002). Given the rich pharmacology of ayahuasca, this study does not address the direct contribution of the serotonergic system in the regulation of P50 suppression. Like the serotonergic system, the effect of dopaminergic modulation on both PPI and P50 in healthy human subjects has also been inconsistent. The dopamine $\mathrm{D}_{2}$ receptor agonist bromocriptine (Abduljawad et al, 1998, 1999), the $D_{1} / D_{2}$ agonist, pergolide (Bitsios et al, 2005), the $\mathrm{D}_{3}$ agonist, ropinirole (Giakoumaki et al, 2007), and the dopamine reuptake inhibitor and releaser, amphetamine (Hutchison and Swift, 1999) and amantadine (Bitsios et al, 2005), have all been shown to reduce PPI, whereas other studies have reported that dopamine agonists including bromocriptine and L-dopa have no effects on PPI (Kumari et al, 1998; Swerdlow et al, 2002a, b). Similarly, amphetamine has been shown to decrease P50 suppression (Light et al, 1999), whereas other studies report no effects of enhancing dopamine neurotransmission with bromocriptine and the 
dopamine precursor L-dopa on P50 suppression (Oranje et al, 2004).

One method that has been increasingly employed in humans to manipulate central serotonin and dopamine neurotransmission is the method of amino-acid precursor depletion (Reilly et al, 1997). On the basis of acute precursor restrictions, endogenous neurotransmitter release is reduced through an ingested suspension of amino acids that lack certain neurotransmitter precursors. In humans, acute tryptophan depletion (ATD) has been shown to acutely decrease concentrations of serotonin and its metabolites (Carpenter et al, 1998; Moja et al, 1988; Nishizawa et al, 1997; Williams et al, 1999), and has been shown to consistently impair serotonin-dependent processes such as memory consolidation and learning (Harrison et al, 2004; Sambeth et al, 2007). Using this method, serotonin depletion was found to decrease PPI in healthy humans (Phillips et al, 2000a). On the other hand, acute tyrosine/phenylalanine depletion (ATPD) has been shown to selectively decrease dopamine synthesis and release (Jaskiw and Bongiovanni, 2004; Leyton et al, 2000; McTavish et al, 1999a,b, 2001a,b; Mehta et al, 2005; Montgomery et al, 2003), and impair dopamine-dependent cognitive processes such as working memory (Harmer et al, 2001; Harrison et al, 2004). The effects of dopamine depletion via ATPD on PPI and P50 suppression are yet to be determined.

To further explore the role of serotonin and dopamine in sensorimotor and sensory gating, we examined the effects of ATD (to decrease serotonin) and ATPD (to decrease dopamine) on PPI and P50 suppression in healthy human participants. In addition, we also examined for the first time, the effects of simultaneous dopamine and serotonin depletion (ie combined monoamine depletion, CMD) on PPI and P50 suppression. CMD has been shown to simultaneously deplete tryptophan, tyrosine, and phenylalanine to levels that are expected to modulate central dopaminergic and serotonergic function (Nathan et al, 2004; Matrenza et al, 2004). Given the inconsistencies in previous findings with regard to the effects of serotonin and dopamine on PPI and P50 suppression, we made no directional hypotheses. No predictions were made concerning the effects of combined dopamine and serotonin depletion, given the novel nature of this investigation.

\section{METHODS}

\section{Participants}

Sixteen healthy non-smoking male volunteers, aged 20-41 years $(M=26,13$ years, $S D=6.70$ years $)$, were included in the study. Participants were recruited through local and university advertisements, and were considered for inclusion if they were non-smoking, not currently taking any medications, had no personal or family history of psychiatric disorders, had no history of substance abuse, and had no history of head injury or neurological disorders. All candidates underwent a semi-structured medical examination and clinical interview performed by a medical physician before participation, to confirm that they were physically and psychiatrically suitable and to ensure that the inclusion criteria were met. Also, all participants gave written informed consent for participation in the study, which was approved by the Swinburne University Human Research Ethics Committee.

\section{Study Design}

This study was a double-blind, placebo-controlled, crossover design in which each participant was tested under four acute treatment conditions; (a) $104 \mathrm{~g}$ nutritionally balanced placebo control treatment (BAL), (b) ATD for serotonin depletion, (c) ATPD for dopamine depletion, and (d) acute tyrosine, phenylalanine, and tryptophan depletion (CMD) for depletion of dopamine and serotonin. The assignment for order of completion of each treatment for each individual was randomized using a computerized randomization program. Completion of each treatment was separated by a minimum 5-day washout period.

\section{Amino-Acid Composition}

The amino-acid composition for the depletion treatments was based on the $104 \mathrm{~g}$ balanced mixture developed by Young et al (1985), and modified for the CMD as outlined by Nathan et al (2004). In the current study, the amino-acid mixture for the balanced control treatment consisted of $5.5 \mathrm{~g}$ of L-alanine, $3.2 \mathrm{~g}$ of glycine, $3.2 \mathrm{~g}$ of L-histidine, $8.0 \mathrm{~g}$ of L-isoleucine, $13.5 \mathrm{~g}$ of leucine, $11.0 \mathrm{~g}$ of L-lysine monohydrochloride, $5.7 \mathrm{~g}$ of L-phenylalanine, $12.2 \mathrm{~g}$ of L-proline, $6.9 \mathrm{~g}$ of L-serine, $6.5 \mathrm{~g}$ of $\mathrm{L}$-threonine, $2.3 \mathrm{~g}$ of L-tryptophan, $6.9 \mathrm{~g}$ of L-tyrosine, and $8.9 \mathrm{~g}$ of L-valine. Additionally, $4.9 \mathrm{~g}$ of L-arginine, $2.7 \mathrm{~g}$ of L-cysteine, and $3.0 \mathrm{~g}$ of $\mathrm{L}$-methionine were encapsulated in 22 gelatin capsules and administered separately due to their unpleasant taste. All treatment mixtures were composed of the same amino acids as in the BAL treatment, but the ATPD mixture was deficient of L-tyrosine and L-phenylalanine for the depletion of dopamine, and the ATD mixture was deficient of L-tryptophan for the depletion of serotonin. The CMD treatment was deficient of L-tryptophan, L-tyrosine, and L-phenylalanine for the simultaneous depletion of dopamine and serotonin.

The powdered suspension was mixed with $180 \mathrm{ml}$ of orange juice immediately before oral ingestion and following administration of the capsules. Participants were advised to swallow the drink as quickly as possible, given the unfamiliar taste and texture of the mixture.

\section{Procedure}

Before each testing session, participants were required to adhere to a 24-h low-protein diet, with their total protein consumption to be less than $20 \mathrm{~g}$ (Young et al, 1985; Harrison et al, 2004). Participants were also required to fast from 1900 hours the evening before each testing day, with the exception of drinking water. A low-protein diet and fasting is thought to enhance monoamine depletion and reduce variability in baseline monoamine levels (Reilly et al, 1997). On arrival for testing, participants were required to complete the Visual Analog Mood Scales (VAMSs) to establish baseline mood, and then had a small sample of blood taken $(12 \mathrm{ml})$ to establish baseline amino-acid levels. 
Participants were then administered the amino-acid drink and capsules, which took approximately $10 \mathrm{~min}$.

During the next $5 \mathrm{~h}$, participants rested and were instructed to refrain from any physical activity. Participants were permitted to study or utilize neutral videos, books, and magazines that were provided. Approximately $2 \mathrm{~h}$ post amino-acid ingestion, participants were provided with a low-protein snack of carrot and apple. Four and a half hours post ingestion, participants were again given the VAMSs to examine mood changes following treatment, and were required to give another sample of blood $(12 \mathrm{ml})$ to establish the amino-acid depletion levels. Five hours post amino-acid depletion, participants completed the tasks associated with the measurement of PPI and P50 suppression. Participants were seated in a comfortable chair, approximately $60 \mathrm{~cm}$ from a computer screen, tested for hearing, and given instructions for each test paradigm. The 5-h latency period was chosen to coincide with the timing of the maximal pharmacokinetic and physiological effects of monoamine depletion, as determined in the previous research (Carpenter et al, 1998; Harrison et al, 2004; Harmer et al, 2001; Leyton et al, 2000; Matrenza et al, 2004; McTavish et al, 1999a; Moja et al, 1988; Mehta et al, 2005; Nathan et al, 2004; Nishizawa et al, 1997; Sambeth et al, 2007; Williams et al, 1999). Upon conclusion of the testing procedure, participants were provided with high-protein snacks to replenish their amino-acid levels. Participants resumed their regular diet between successive testing sessions.

\section{Prepulse Inhibition of the Acoustic Startle Response}

The acoustic startle response was measured from the orbicularis oculi muscle EMG activity, recorded as the difference between two $6 \mathrm{~mm}$ electrodes placed below the right eye. Stimuli were generated with a Neuroscan STIM2 audio system and software (NeuroScan Labs, Sterling, VA), and presented to participants binaurally via EAR insert earphones (Aearo Company Auditory System, Indianapolis, IN). EMG activity was digitized continuously at $2000 \mathrm{~Hz}$, amplified and band-pass filtered $(0.05-500 \mathrm{~Hz})$ using a Neuroscan Synamps system.

Acoustic startle testing was similar to the procedure used by Gogos et al (2006) and comprised a total of 24 trials consisting 8 trials of the startle stimuli (ie pulse alone (PA)), to allow for habituation in order to obtain an accurate measure of startle amplitude (Gogos et al, 2006), 8 trials of PA stimuli, and 8 trials each of PA and prepulse stimuli (ie prepulse-PA (PP)), with the trials of PA and PP presented in a pseudo-random order. The inter-trial intervals ranged from 16 to $24 \mathrm{~s}(\mathrm{M}=20 \mathrm{~s})$. Throughout the testing session $70 \mathrm{~dB}$ of white noise continued, following an initial 1-min acclimation period. The startle pulse was a $40 \mathrm{~ms}$ burst of white noise, $38 \mathrm{~dB}$ above background $(108 \mathrm{~dB})$, with $<1 \mathrm{~ms}$ rise/fall time, and prepulses were $20 \mathrm{~ms}$ bursts of white noise, $15 \mathrm{~dB}$ above the background noise $(85 \mathrm{~dB})$, and preceding the startle pulse by $60 \mathrm{~ms}$ (lead interval). A visual task was given to the participants during the startle paradigm to control their attention-participants were instructed to look at the computer screen and press a keypad when a face without a nose appeared, as opposed to a face with a nose. The advantage of the task is that it controls the level of attentional demand, as attention has been shown to modulate PPI and it has been suggested that in the case of uninstructed studies, attention is unconstrained and hence the effects of attention on PPI are unknown (Kedzior and Martin-Iverson, 2007).

The EMG recordings were epoched ( -80 to $300 \mathrm{~ms}$ post stimulus), band-pass filtered $(10-200 \mathrm{~Hz})$, rectified, smoothed (over five adjacent data points and three consecutive passes), and baseline corrected as indicated by Anokhin et al (2003). The magnitude of the startle response was defined as the peak EMG response within 20$120 \mathrm{~ms}$ post stimulus (Balaban et al, 1986), as determined by the NeuroScan software. \%PPI was calculated as (PA-PP/ $\mathrm{PA}) \times 100$, with higher percentages indicating greater inhibition (ie more sensorimotor gating). Following methods used in our previous studies (Gogos et al, 2006), two participants were classified as 'non-responders' and excluded from further statistical analysis, as the peak startle amplitude was less than 0.3 (arbitrary units) in the placebo treatment condition. A third participant was also classified as a non-responder as they did not demonstrate PPI in the placebo treatment condition (ie subjects needed to demonstrate pre-pulse inhibition in the placebo treatment condition to examine the effects of dopamine and serotonin depletion on prepulse inhibition).

\section{P50 Suppression of the ERP}

EEG was recorded using an electrocap (tin electrodes) with 62 scalp sites located according to the International 10-20 System. Impedances were below $5 \mathrm{k} \Omega$ at the start of the recording. EEG data at the $\mathrm{Cz}$ electrode (ie where the P50 ERP has been shown to have maximum activity; Clementz et al, 1998), located at the vertex, was continuously digitized at $500 \mathrm{~Hz}$, amplified and band-pass filtered $(0.01-100 \mathrm{~Hz})$ using the Neuroscan Synamps system.

Two mastoid electrodes placed behind the left and right ears were used as reference electrodes. Fifty-two $80 \mathrm{~dB}$ click pairs with a $500 \mathrm{~ms}$ interclick interval were relayed to the participant binaurally through ear inserts, every 8-12 s $(\mathrm{M}=10 \mathrm{~s})$. Clicks were $1 \mathrm{~ms}$ duration square waves with near instantaneous rise and fall times $(<1 \mathrm{~ms})$. Background noise was continuous $70 \mathrm{~dB}$ white noise, as in the PPI recording. Participants were given the same nose/no nose task as in the PPI paradigm, to control for attention. EEG data were epoched from -200 to $500 \mathrm{~ms}$ post stimulus, continuously digitized at $500 \mathrm{~Hz}$ with a $10-47 \mathrm{~Hz}$ bandpass ( $24 \mathrm{~dB}$ /octave roll-off). Before averaging, epochs were manually inspected and rejected if they contained substantial movement artifacts. The epoched data were then averaged; averages were calculated for each participant in each treatment group, and for the response to the first stimulus, and also for the second stimulus separately.

The P50 auditory evoked potential was chosen based on a few criteria. The P50 in response to the onset of Click 1 (SI, conditioning click) was taken as the most positive peak occurring 38-78 ms post stimulus/click (Croft et al, 2004). The P50 peak needed to be preceded by a negative deflection, $\mathrm{Na}$, occurring between 25 and $50 \mathrm{~ms}$, and a positive deflection, $\mathrm{Pa}$, occurring between 15 and $40 \mathrm{~ms}$ post stimulus (Croft et al, 2004). Where $\mathrm{Pa}$ or $\mathrm{Na}$ components could not be identified, the larger positive deflection 
occurring between 40 and $80 \mathrm{~ms}$ was considered to be the P50 waveform. Additionally, the P50 peak had to occur within $\pm 15 \mathrm{~ms}$ of the P50 identified in the grand average, and the $\mathrm{Na}$ and $\mathrm{Pa}$ had to occur within $\pm 10 \mathrm{~ms}$ of the $\mathrm{Na}$ and $\mathrm{Pa}$ deflections in the grand average. For the second click (S2, test click), the P50 peak was selected as the most positive wave occurring during a latency range equal to the latency of the conditioning response $\pm 10 \mathrm{~ms}$. These criteria for latency were used to help ensure that the paired responses represented the same waveform (Nagamoto et al, 1991). In addition to the above criteria, the P50 peaks had to exhibit positive fronto-central distributions, which were manually classified using two-dimensional topographic maps (Croft et al, 2004). P50 amplitude was defined as the difference between the P50 peak and the preceding negative trough, for each of the conditioning and test P50. P50 suppression ratio was calculated according to the following formula: $((1-\mathrm{S} 2 / \mathrm{S} 1) \times 100)$, where $\mathrm{S} 2$ is the test P50 amplitude and $\mathrm{S} 1$ is the conditioning P50 amplitude. Lower P50 suppression values indicate reduced sensory gating. Two participants were classified as 'outliers' because they had ratios greater than $3 \mathrm{SD}$ from the mean, and were excluded from further analysis.

\section{Subjective Mood Assessment}

Subjective mood ratings were obtained using the VAMSs (Bond and Lader, 1974). The VAMS consists of 16 bipolar scales, anchored at each end of a $100 \mathrm{~mm}$ line. In factor analyses, these scales reduce to three subscales: alertness (nine items), contentedness (five items), and calmness (two items).

\section{Biochemical Analysis}

Upon collection, the venous blood samples $(12 \mathrm{ml})$ were separated by centrifugation for $20 \mathrm{~min}$ at 3000 r.p.m. and the resulting plasma stored at $-20^{\circ} \mathrm{C}$. Using precolumn derivatization with 6-aminoquinolyl- $N$-hydroxysuccinimidyl carbamate (AQC), concentrations in plasma of the free amino acids tryptophan (TRP), tyrosine (TYR), phenylalanine (PHE), valine (VAL), leucine (LEU), and isoleucine (ILE) were then calculated. The derivatives were then separated and quantified by reversed-phase high-performance liquid chromatography (HPLC) (Cohen, 2001). The amino acids (with the exception of TRP) were detected by fluorescence, whereas TRP required UV detection. VAL, LEU, and ILE levels were analyzed for the purpose of calculating the ratio of plasma TRP, TYR, or PHE, to these other large neutral amino acids (LNAAs). The ratio of precursors to other LNAAs has been suggested to be a more accurate indicator of central precursor depletion than absolute plasma precursor levels, due to the competition between the LNAAs for brain entry via the same AA transporter (Oldendorf and Szabo, 1976).

Before derivatization, the plasma samples $(100 \mu \mathrm{l})$ were diluted $1: 1$ with internal standard solution and deproteinized by ultrafiltration through a membrane with a $10 \mathrm{kDa}$ nominal molecular weight cutoff (Ultrafree MC with PL-10 membrane, Millipore, MA, USA). The filtrate $(100 \mu \mathrm{l})$ was then put through AQC derivatization and HPLC analysis using the Waters AccTag amino-acid analysis system (Waters Corporation, MA, USA) (Cohen, 2001).

\section{Statistical Analysis}

As the biochemical data were not normally distributed and could not be transformed to normality, this was analyzed with non-parametric Friedman's tests. Significant results were followed up with the Wilcoxon's signed ranks test.

PPI data were normalized using the inverse log transformation t_data $=\ln (300$-data). To examine the amount of PPI, a paired samples $t$-test with trial type (PA or PP) as the within-subject factor was conducted on the data from the balanced placebo control treatment. \%PPI scores and PA startle magnitudes were then analyzed with separate one-way repeated measures ANOVAs with treatment (BAL, CMD, ATD, ATPD) as the within-subject factor. Similarly, to determine whether P50 suppression occurred in the present sample, a paired sample $t$-test with click type (S1 or S2) the within-subject factor was conducted on the P50 data from the balanced placebo control treatment. P50 ratio scores were then analyzed using a one-way repeated measures ANOVA with treatment as the within-subject variable.

VAMS data were analyzed using a 4 (treatment: BAL, ATD, ATPD, CMD) by 3 (subscale: alertness, contentedness, calmness) by 2 (time: baseline, post-treatment) repeated measures ANOVA.

\section{RESULTS}

\section{Amino-Acid Concentrations}

Friedman's test showed a significant effect of treatment on the plasma levels of the amino acids (tryptophan, tyrosine, and phenylalanine) $\left(\chi^{2}(23)=148.41 ; p=0.0004\right)$. Follow-up Wilcoxon's signed ranks tests (with significance set at $p<0.05)$ revealed significant increases in all amino acids post administration of the BAL treatment, and significant decreases in all amino acids post administration of the CMD treatment, when compared to baseline concentrations of amino acids. Following ATD, there was a significant decrease in the concentration of TRP and a significant increase in PHE concentration, but no significant change in concentration of TYR, when compared to baseline levels. After the ATPD treatment there was a significant increase in TRP levels, as well as significant decreases in TYR and PHE levels, when compared to baseline concentrations. For percentages see Table 1 .

A separate Friedman's test also showed a significant effect of treatment on the amino-acid ratios $\left(\chi^{2}(23)=138.06\right.$, $p=0.0004)$. Follow-up Wilcoxon's signed ranks test (with significance set at $p<0.05$, two-tailed) revealed that after the BAL treatment, there was a small but significant decrease in the ratio of TYR: $\Sigma$ LNAAs, but no significant change in the ratios of TRP : $\Sigma$ LNAAs or PHE: $\Sigma$ LNAAs, when compared to baseline amino-acid ratios. Following the CMD treatment, there was a significant reduction from baselines in all amino-acid ratios. Following ATD, there was significant reduction in the ratio of TRP/ $\Sigma$ LNAAs; however, there were no significant decreases in the ratio of TYR: $\Sigma$ LNAAs or PHE: $\Sigma$ LNAAs, when compared to baseline ratios. Lastly, 
Table I Plasma Concentrations of Amino Acids $\left(\mu \mathrm{mol} \mathrm{I}^{-1}\right)$ (Mean, SD)

\begin{tabular}{|c|c|c|c|c|}
\hline Amino acid & $\begin{array}{l}\text { Treatment } \\
\text { condition }\end{array}$ & Baseline & $4 \mathrm{~h}$ post-treatment & $\begin{array}{l}\text { Percent } \\
\text { change }\end{array}$ \\
\hline \multirow[t]{3}{*}{ Plasma-free TRYP } & BAL & $4.53(1.88)$ & $10.94(3.42)$ & |4|.50*** \\
\hline & ATD & $5.10(1.61)$ & $0.80(0.23)$ & $-84.3 \mid$ *** \\
\hline & ATPD & $4.23(1.92)$ & I5.07 (7.78) & 256.26 *** \\
\hline \multirow{2}{*}{ Plasma TYR } & ATD & $65.49(46.78)$ & 96.74 (36.59) & 47.72 \\
\hline & ATPD & $46.73(14.02)$ & $12.93(4.42)$ & $-72.33^{*} *$ \\
\hline \multirow[t]{3}{*}{ Plasma PHE } & BAL & $44.96(9.31)$ & $101.74(43.86)$ & 126.29** \\
\hline & CMD & $43.90(8.77)$ & $8.04(3.12)$ & $-81.69 * *$ \\
\hline & ATD & $50.3 \mid(|4.5|)$ & | 4.37 (52.3|) & 127.33* \\
\hline \multirow{2}{*}{$\mathrm{TRP} / \Sigma \mathrm{LNAAs}$} & ATD & $0.015(0.005)$ & $0.001(0.001)$ & $-93.33^{* * *}$ \\
\hline & ATPD & $0.014(0.008)$ & $0.016(0.006)$ & 14.29 \\
\hline \multirow[t]{4}{*}{ TYR/ $\Sigma$ LNAAs } & BAL & $0.162(0.031)$ & $0.109(0.024)$ & $-32.72 * *$ \\
\hline & CMD & $0.161(0.033)$ & $0.015(0.005)$ & $-90.68 * *$ \\
\hline & ATD & $0.162(0.030)$ & $0.131(0.060)$ & -19.14 \\
\hline & ATPD & $0.149(0.059)$ & $0.015(0.005)$ & $-89.93 * *$ \\
\hline \multirow[t]{4}{*}{$\mathrm{PHE} / \Sigma \mathrm{LNAAs}$} & BAL & $0.149(0.022)$ & $0.111(0.033)$ & -25.50 \\
\hline & CMD & $0.149(0.023)$ & $0.011(0.004)$ & $-92.62 * *$ \\
\hline & ATD & $0.142(0.034)$ & $0.140(0.034)$ & -1.41 \\
\hline & ATPD & $0.134(0.027)$ & $0.009(0.003)$ & $-93.28 * *$ \\
\hline
\end{tabular}

ATD, acute tryptophan depletion condition; ATPD, acute tyrosine/phenylalanine depletion condition; BAL, balanced condition; CMD, combined monoamine depletion condition; LNAAs, large neutral amino acids.

* $p<0.05 ; * *$ * $<0.02$

following the ATPD condition, there were significant reductions in the ratio of TYR: $L$ LNAAs and PHE: $\Sigma$ LNAAs; however, there was no significant change in the ratio of TRP: $\Sigma$ LNAAs, when compared to baseline ratios. For percentages see Table 1.

To establish whether depletion levels achieved after the CMD treatment were equivalent to those achieved after the ATD and ATPD treatments, percentage change of the amino-acid ratios ((post-pre/pre)*100) was compared across the treatment conditions. Wilcoxon's signed ranks test (with significance set at $p<0.05$ ) revealed no significant difference in percentage change in the ratios of TYR: $\Sigma$ LNAAs or PHE: $\Sigma$ LNAAs between ATPD and CMD treatments. Additionally, there was no significant difference in the percentage change of the ratio of TRP: $L$ LNAAs, between the ATD and CMD treatments.

\section{Prepulse Inhibition}

A paired samples $t$-test comparing PA and PP magnitudes in the BAL treatment revealed larger startle responses on PA trials when compared to PP trials (ie significant PPI) $(t(12)=2.40, p=0.03) \quad$ (Figure 1$)$. A one-way repeated measures ANOVA revealed no significant difference in startle magnitude (ie PA trials) across the four treatment conditions $(\mathrm{F}(3,36)=1.15, p=0.27$; Figure 1$)$. In contrast, a

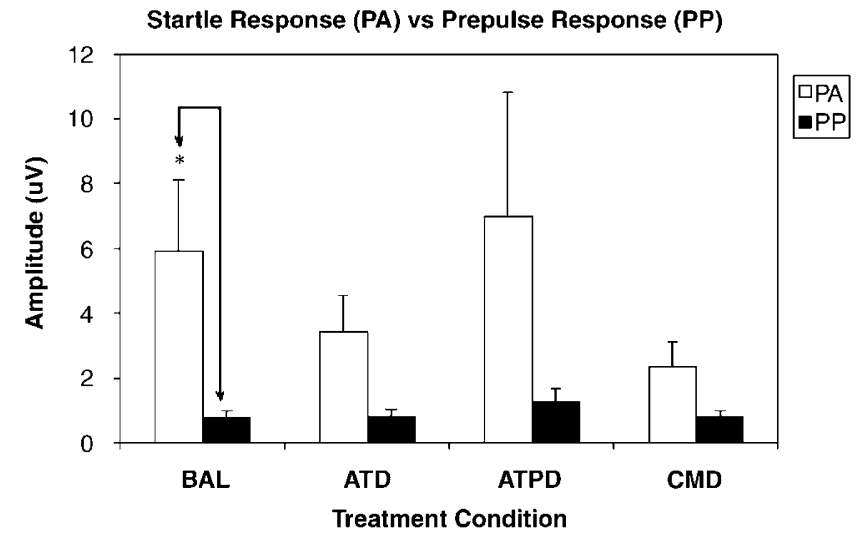

Figure I Mean PA and PP startle magnitude in the ATD, ATPD, and CMD treatment conditions compared with the BAL treatment. *Significant difference between $\mathrm{PA}$ and $\mathrm{PP}$ in the BAL treatment $(p<0.05)$. ATD, tryptophan depletion; ATPD, tyrosine/phenylalanine depletion; BAL, placebo control; CMD, combined tryptophan, tyrosine, and phenylalanine depletion; PA, pulse alone; PP, prepulse. Results expressed as mean \pm SEM.

one-way repeated measures ANOVA revealed a significant main effect of treatment on \%PPI $(\mathrm{F}(3,36)=2.92, p=0.047$, partial $\left.\eta^{2}=0.20\right)$. Simple planned contrasts indicated that there were significant reductions in \%PPI after both the 
CMD treatment $\left(\mathrm{F}(1,12)=5.66, p=0.035\right.$, partial $\left.\eta^{2}=0.32\right)$, and the ATD treatment $(\mathrm{F}(1,12)=4.78, p=0.049$, partial $\left.\eta^{2}=0.29\right)$, when compared to the BAL treatment. However, there was no significant change in \%PPI after the ATPD treatment $(F(1,12)=3.14, p=0.102$; Figure 2). Furthermore, simple planned contrasts showed no significant differences in the latency to startle peak in the CMD $(\mathrm{F}(1,12)=1.12, p=0.311), \operatorname{ATD}(\mathrm{F}(1,12)=0.145, p=0.71)$,

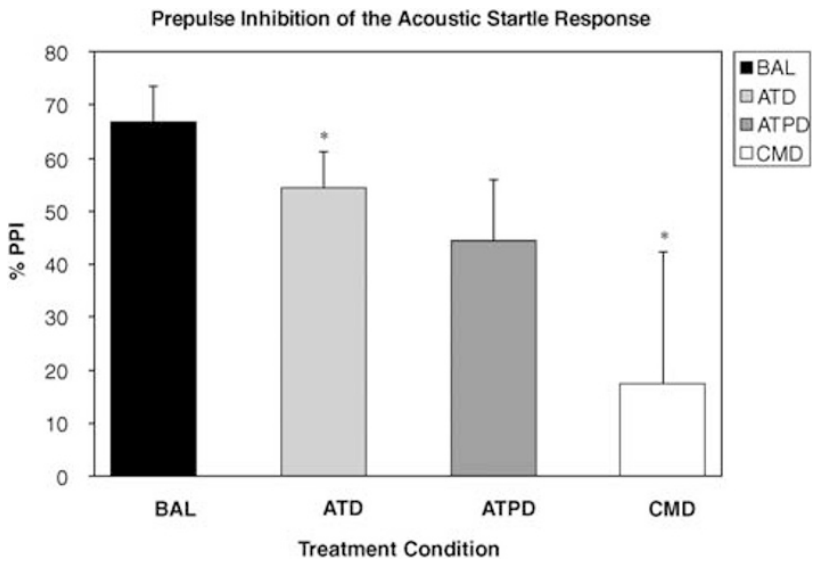

Figure 2 Percentage PPI of startle response in the ATD, ATPD, and CMD treatment conditions compared with the BAL treatment. ATD, tryptophan depletion; ATPD, tyrosine/phenylalanine depletion; BAL, placebo control; CMD, combined tryptophan, tyrosine, and phenylalanine depletion. *Significant reduction in percentage inhibition in the ATD and CMD treatments when compared to the BAL treatment $(p<0.05)$. Results are expressed as mean \pm SEM.
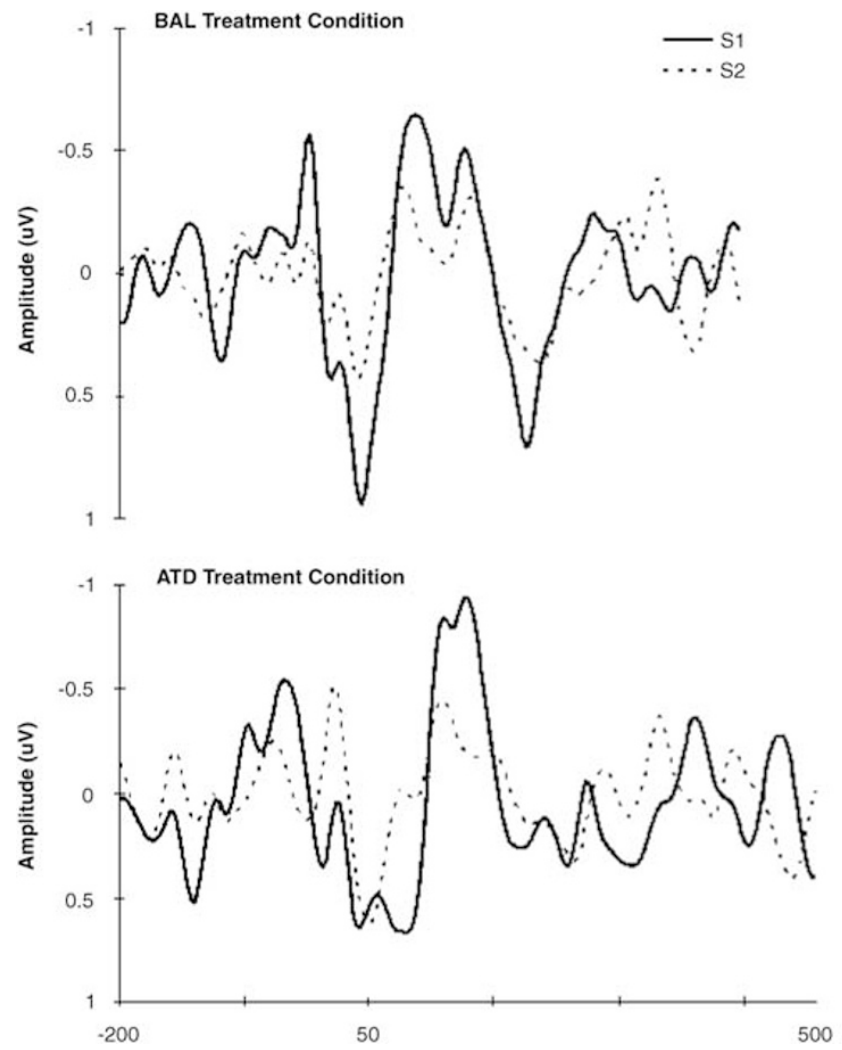

or ATPD treatments $(\mathrm{F}(1,12)=4.43, p=0.057)$ when compared to the BAL treatment condition.

\section{P50 Suppression}

As with PPI, a paired samples $t$-test comparing T1 and T2 amplitudes in the BAL treatment revealed larger P50 amplitudes to $\mathrm{T} 1$ than $\mathrm{T} 2$ (ie significant P50 suppression) $(t(12)=5.52, p=0.0004$; Figures 3 and 4$)$. A one-way repeated measures ANOVA of the T2/T1 ratio revealed a

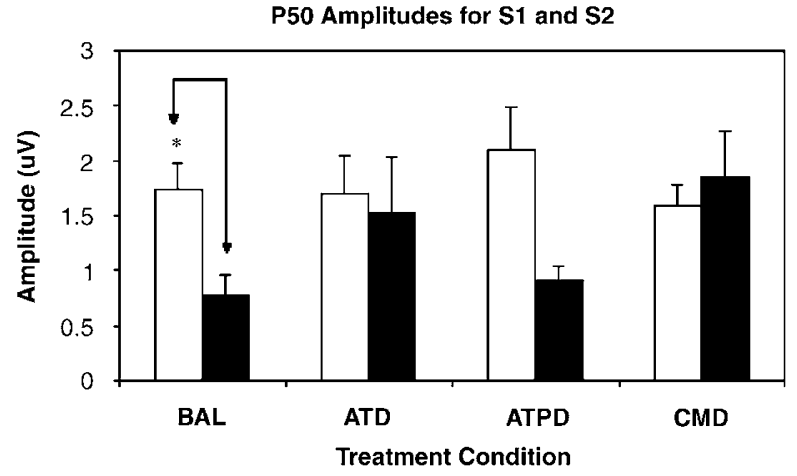

Figure 4 Mean P50 amplitudes for Click I (SI) and Clink 2 (S2) in the ATD, ATPD, and CMD treatment conditions compared with the BAL treatment. ATD, tryptophan depletion; ATPD, tyrosine/phenylalanine depletion; BAL, placebo control; CMD, combined tryptophan, tyrosine, and phenylalanine depletion. *Significant difference between amplitude of SI compared to amplitude of S2 in the BAL treatment $(p<0.00$ I). Results are expressed as mean \pm SEM.
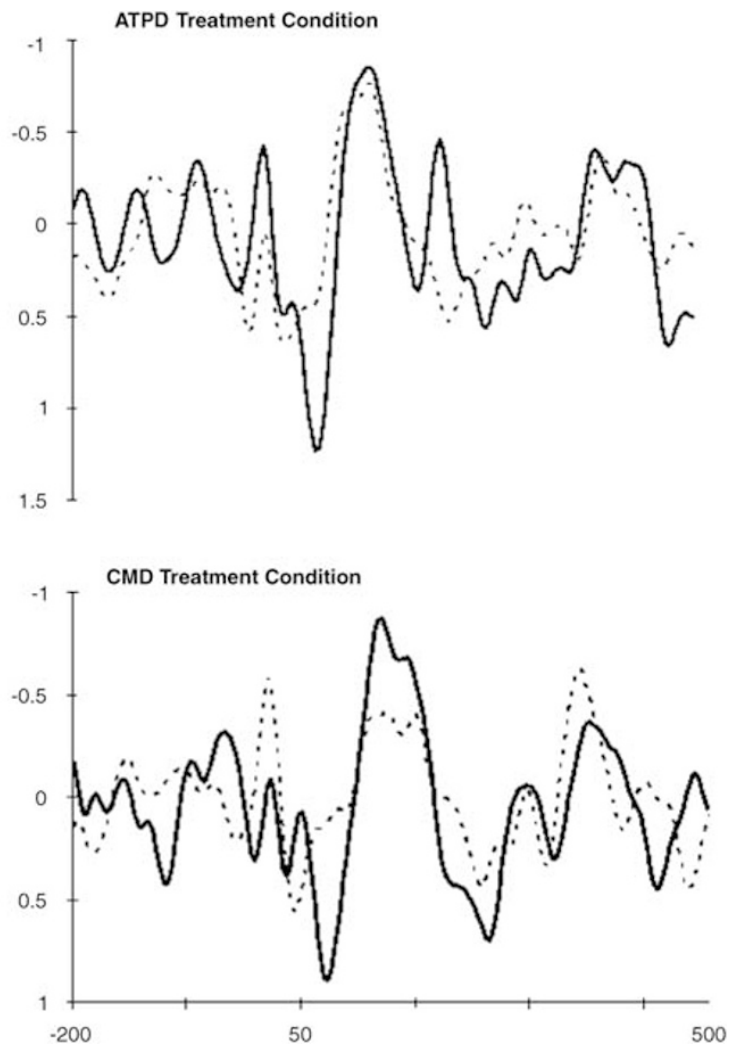

Figure 3 Grant average P50 waveforms for the ATD, ATPD, and CMD treatment conditions compared with the BAL treatment condition. 


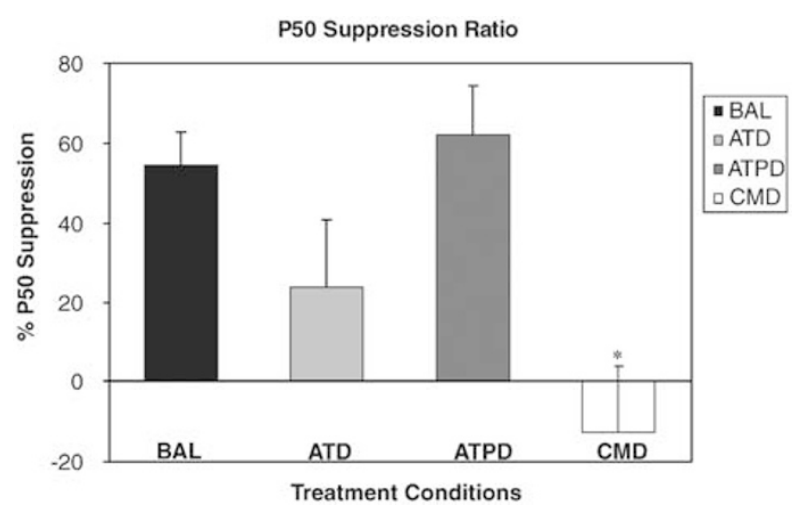

Figure 5 P50 suppression ratio in the ATD, ATPD, and CMD treatment conditions compared with the BAL treatment. ATD, tryptophan depletion; ATPD, tyrosine/phenylalanine depletion; BAL, placebo control; CMD, combined tryptophan, tyrosine, and phenylalanine depletion. *Significant decrease in P50 suppression in the CMD compared to the BAL treatment $(* 0=0.00)$. Results are expressed as mean \pm SEM.

significant main effect of treatment $(\mathrm{F}(3,36)=4.63$, $p=0.008$, partial $\eta^{2}=0.28$ ). Simple planned contrasts indicated that there was a significant increase in the P50 ratio (ie decrease in P50 suppression) after the CMD treatment condition, when compared with the balanced control treatment $(\mathrm{F}(1,13)=24.49, \quad p=0.00$, partial $\eta^{2}=0.36$ ); however, there was no difference in the P50 ratio after either the $\operatorname{ATD}(\mathrm{F}(1,13)=3.44$, $p=0.086)$ or $\operatorname{ATPD}(\mathrm{F}(1,13)=0.23, p=0.64)$ treatments (Figure 5).

\section{Subjective Mood Assessment}

Repeated measure ANOVA showed no significant treatment by time interaction $(\mathrm{F}(3,39)=0.59, p=0.63)$, and no VAMS subscale by treatment by time interaction $(\mathrm{F}(6,78)=1.35$, $p=0.09$ ), suggesting no significant changes in the mood following any of the treatment conditions for VAMS subscales, alertness, contentedness, and calmness.

\section{DISCUSSION}

The current study investigated the effects of selective and combined serotonin and dopamine depletion on measures of 'sensorimotor gating' (ie PPI) and 'sensory gating' (ie P50 suppression), in healthy male subjects. Depletion of serotonin via tryptophan depletion significantly disrupted PPI, but had no effect on P50 suppression, whereas dopamine depletion via tyrosine/phenylalanine depletion had no significant effect on either PPI or P50 suppression. Lastly, the simultaneous depletion of dopamine and serotonin via tryptophan, tyrosine, and phenylalanine depletion resulted in significant reductions in both PPI and P50 suppression. These findings were observed independent of any mood effects and provide evidence for differential modulation of PPI and P50 suppression measures of sensorimotor and sensory gating, respectively, by both serotonin and dopamine in humans.

\section{Serotonin Depletion}

ATD induced a $93 \%$ decrease in the ratio of tryptophan to other LNAAs, a decrease that is comparable to, if not exceeding, that obtained in other studies (Schmitt et al, 2000; Sobczak et al, 2002; Sambeth et al, 2007). Furthermore, decreases of such a magnitude have been shown to significantly affect brain serotonin synthesis (Moja et al, 1988; Nishizawa et al, 1997), CSF concentrations of serotonin metabolites (Carpenter et al, 1998; Williams et al, 1999), and serotonin-dependent cognitive processes (Sambeth et al, 2007). Following ATD we observed impairments in sensorimotor gating, as evidenced by a reduction in PPI. This finding directly supports a number of studies that have similarly found a decrease in PPI following a reduction in serotonergic neurotransmission in healthy humans, with ATD (Phillips et al, 2000a), the 5- $\mathrm{HT}_{2}$ receptor antagonist ketanserin (Graham et al, 2002), and the 5- $\mathrm{HT}_{1 \mathrm{~A}}$ partial agonist buspirone (Gogos et al, 2006). The findings also concur with a number of studies that report the opposite effect (ie an increase in PPI with enhancement of serotonergic neurotransmission) with MDMA (Liechti et al, 2001) and the 5- $\mathrm{HT}_{2 \mathrm{~A} / 1 \mathrm{~A}}$ agonist psilocybin (Gouzoulis-Mayfrank et al, 1998; Vollenweider et al, 1999). However, serotonergic manipulation has not consistently modulated PPI in all studies in humans, with some studies reporting no effects on PPI following acute enhancement of synaptic serotonin with the serotonin reuptake inhibitors, fenfluramine (Abel et al, 2007), fluvoxamine (Phillips et al, 2000b), citalopram (Liechti et al, 2001), and escitalopram (Jensen et al, 2007); and other studies reporting a reduction in PPI or no effects on PPI (depending on the ISI) with psilocybin (Vollenweider et al, 2007).

While the reason for this inconsistency is unclear, there are some important possibilities worth discussing. First, it is possible that differences between studies may relate to the selectivity or potency of the drugs or manipulations for the serotonergic system. It could be argued that the positive effects of MDMA and psilocybin may be mediated by their effects on other neurotransmitter systems, including dopamine or noradrenaline, rather than their serotonergic actions. However, this is unlikely as we and others have shown a decrease in PPI following ATD (in this study and Phillips et al, 2000a) and with the $5-\mathrm{HT}_{1 \mathrm{~A}}$ agonist, buspirone (Gogos et al, 2006). It is more likely that effects are related to the potency of serotonergic modulation. Indeed animal studies have shown evidence for dose-dependant effects of serotonin depletion (Prinssen et al, 2002) and serotonin agonists (Geyer et al, 2001; Vollenweider et al, 2007) on PPI. Secondly, it is possible that differences between studies may be related to the stimulus characteristics of the PPI paradigm (eg the interval between prepulse and pulse) and their subsequent sensitivity to serotonergic manipulation. In support, Vollenweider et al (2007) recently reported an effect on PPI that was dependent on the interval between prepulse and pulse (ie lead interval), with psilocybin reducing PPI at short $(30 \mathrm{~ms})$, having no effects at medium $(60 \mathrm{~ms})$, and increasing PPI at long (120-2000 ms) intervals. Similar effects have also been reported with MDMA (Liechti et al, 2001). Finally, differences between studies may be related to methodological differences in the samples selected. Only a few studies, including the current study, 
have controlled for smoking (Liechti et al, 2001; Gogos et al, 2006) and menstrual cycle phase (Liechti et al, 2001; Gogos et al, 2006; Vollenweider et al, 2007). This is critical as both smoking (Della Casa et al, 1998) and changes in menstrual cycle phase (Swerdlow et al, 1997) have been reported to influence PPI.

In contrast, after ATD we did not observe a significant difference in P50 suppression, suggesting that P50 suppression is not modulated by acute changes in serotonergic neurotransmission. This finding is inconsistent with a report showing a reduction in P50 suppression with the $5-\mathrm{HT}_{2 \mathrm{~A} / 2 \mathrm{C}}$ receptor agonist ayahuasca (Riba et al, 2002). However, the latter findings should be interpreted with caution, as ayahuasca has multiple pharmacological actions in addition to its $5-\mathrm{HT}_{2 \mathrm{~A} / 2 \mathrm{C}}$ receptor agonistic properties, and hence the P50 suppression reduction could not be attributed specifically to serotonergic effects. Two other studies in patients with schizophrenia reported increases in P50 suppression with the $5-\mathrm{HT}_{3}$ antagonists odansetron and tropisetron (Adler et al, 2005; Koike et al, 2005), providing some evidence for serotonergic regulation of P50 suppression. However, the latter studies were conducted in patients with schizophrenia who were on atypical antipsychotics and these drugs have multiple pharmacological effects, making it difficult to elucidate the exact mechanisms responsible for the P50 increases. A likely possibility is that the effects are mediated by modulation of the cholinergic system. A link between P50 suppression and nicotinic receptors has been reported previously (Adler et al, 1986, 1992; Freedman et al, 1997), and tropisetron has been shown to modulate P50 suppression via effects on nicotinic receptors (Hashimoto et al, 2005).

In summary, current findings provide evidence for neurochemical differentiation with regard to the effects of selective serotonergic modulation on PPI and P50 suppression. These findings add to the growing body of evidence suggesting that these paradigms may in fact be assessing different neural mechanisms.

\section{Dopamine Depletion}

ATPD resulted in an $83 \%$ reduction in the ratio of tyrosine to other LNAAs, and a 93\% reduction in the ratio of phenylalanine to other LNAAs. These depletion levels are equivalent to those observed using ATPD in previous studies (Harmer et al, 2001; Leyton et al, 2000). Furthermore, APTD studies with depletion levels of this magnitude have noted significant reductions in catecholamine metabolites (Palmour et al, 1998) and catecholamine synthesis (Jaskiw and Bongiovanni, 2004; McTavish et al, 1999a, b), and significant increases in plasma prolactin levels (an indirect measure of dopamine function) (Harmer et al, 2001). However, depletion of dopamine with ATPD in the present study resulted in no significant change in either PPI or P50 suppression. These findings are contrary to a number of reports showing evidence for dopaminergic modulation of PPI and P50 suppression in healthy human subjects. For example, the dopamine $\mathrm{D}_{2}$ receptor agonist bromocriptine (Abduljawad et al, 1998, 1999), the $\mathrm{D}_{1} / \mathrm{D}_{2}$ agonist, pergolide (Bitsios et al, 2005), the $\mathrm{D}_{3}$ agonist, ropinirole (Giakoumaki et al, 2007), and the dopamine reuptake inhibitor and releaser, amphetamine (Hutchison and Swift, 1999; Light et al, 1999) and amantadine (Bitsios et al, 2005) have all been shown to reduce either PPI and/or P50 suppression. However our findings do support a number of other studies in healthy human subjects that have failed to find robust effects on PPI or P50. For example, studies have shown that augmenting dopamine neurotransmission with the dopamine agonists amphetamine, bromocriptine, pergolide, and L-dopa have no effects on PPI and P50 suppression (Kumari et al, 1998; Swerdlow et al, 2002a, b; Oranje et al, 2004).

Although the reasons for the inconsistency are not clear, it is possible that differences in sample characteristics as well as in dose and pharmacokinetics of the drugs may account for some of the discrepancies. Alternatively, as reported in animals (Martin-Iverson and Else, 2000; Swerdlow et al, 2001, 2002b, c) and as discussed for the serotonin section, inconsistencies may be related, in part, to differences in PPI stimulus parameters including lead intervals and their sensitivity to dopaminergic modulation. Furthermore, there is increasing evidence that the effects of dopaminergic drugs on PPI may be related to baseline PPI, with greater reductions reported in subjects with high baseline PPI (Bitsios et al, 2005; Giakoumaki et al, 2007). This may also be extended to P50 effects, as baseline P50 suppression differences have been reported according to differences in the functional allelic catechol-O-methyltransferase polymorphism with valine homozygous subjects exhibiting the greatest P50 suppression deficits (Lu et al, 2007).

Another critical factor that could explain the variability in the findings is a possible imbalance in dopamine neurotransmission (ie away from an optimal level) following dopaminergic modulation. Consistent with this assertion, one prominent hypothesis describes an inverted ' $U$ '-shape representation of dopamine function within frontal networks (Arnsten and Goldman-Rakic, 1998; Goldman-Rakic, 1995). In this model there is a restricted range of DA stimulation for optimal prefrontal function, and any significant change in neurotransmission, that is, either too little stimulation (DA receptor blockade) or too much stimulation (such as that which occurs when exposed to stress) results in DA dropping out of the normal functioning range, and hence impairment of dopamine-dependent prefrontal functions (Arnsten and Goldman-Rakic, 1998). At the cellular level similar findings have also been observed, with prefrontal neurons also appearing to exhibit an inverted $U$ response to $D_{1}$ receptor stimulation (Williams and Goldman-Rakic, 1995). In support of the importance of optimal dopamine stimulation in the regulation of gating, Moxon et al (2003a, b) have developed a computer model of dopaminergic modulation of the P50 ERP in the hippocampus, which can explain the relationships between sensory gating and dopaminergic function in schizophrenia. They found both excessive and reduced dopamine levels attenuated sensory gating responses by modulating the signal-to-noise ratio in the prefrontal cortex. Excessive dopamine increases the likelihood of neuronal firing causing the neurons to become hyper-responsive. In this state, cells in the neural circuits lose the ability to be activated synchronously by auditory stimuli. Given that synchronous activity is then not available to create large amplitude responses, the P50 amplitude is reduced. 
Excessive activation of dopaminergic receptors can also result in an increase in the background amplitude of the EEG, such that when a P50 signal is produced to an auditory stimulus, it cannot be seen above the background level of noise. Similarly, reduced synchronous activity occurred when dopaminergic activity was very low, thus resulting in decreased P50 amplitudes.

In the current study, as selective depletion of dopamine had no effects on either measure of gating, we suggest that the amount of dopamine depletion achieved with ATPD was still within the range required for optimal performance. This is likely given that tyrosine/phenylalanine depletion is thought to be a mild challenge for the dopamine system, with studies showing relatively small changes on physiological and neurochemical measures of dopamine function. For example, tyrosine/phenylalanine depletion has been found to induce only a $6 \%$ increase in $\left[{ }^{11} \mathrm{C}\right]$ raclopride binding, which may correspond to an approximate $10-20 \%$ reduction in dopamine concentrations (Montgomery et al, 2003). Additionally, it appears to induce only a modest increase in plasma prolactin levels (Harmer et al, 2001; Montgomery et al, 2003). Furthermore, modest or no effects of tyrosine depletion have been noted on dopaminedependent cognitive processes, such as working memory (Ellis et al, 2007; Harmer et al, 2001; Harrison et al, 2004). Hence it is possible that our study on dopamine depletion, as well as that of others investigating the effects of dopamine agonists on PPI and/or P50 suppression (Kumari et al, 1998; Swerdlow et al, 2002a, b; Oranje et al, 2004), may have not caused significant changes in dopamine neurotransmission to the level required for disruption of either sensorimotor or sensory gating. The findings of an amphetamine-induced reduction in PPI only in smokers (Kumari et al, 1998) (ie causing larger increases in dopamine neurotransmission and pushing these subjects downward the putative inverted $U$ curve) and the dopamine agonist-induced reduction in PPI in subjects with high baseline PPI (Bitsios et al, 2005) (ie causing larger increases in dopamine neurotransmission in subjects who may already have higher baseline dopamine and thus causing a similar downward shift in the inverted U curve), support the possibility that the relationship between dopamine neurotransmission and sensorimotor or sensory gating may follow an inverted U-type relationship.

In summary, our findings indicate no changes in PPI and P50 suppression following selective depletion of dopamine with ATPD, and support the findings of a number of studies using dopamine agonists. However, the effects of dopamine on PPI and P50 suppression may depend on the relative dopamine tone, with too much or two little dopamine neurotransmission impairing sensorimotor or sensory gating.

\section{Combined Serotonin and Dopamine Depletion}

CMD with acute tryptophan, tyrosine, and phenylalanine depletion induced an $86 \%$ reduction in the ratio of tryptophan to other LNAAs, together with a $90 \%$ decrease in the ratio of tyrosine to other LNAAs, and a $92 \%$ decrease in the ratio of phenylalanine to other LNAAs. These levels of depletion were not statistically different from the levels achieved under the selective depletion of tryptophan, or of tyrosine/phenylalanine, indicating that all three monoamine precursors were depleted simultaneously to levels that are expected to affect central neurotransmitter function (Nathan et al, 2004). Interestingly, this simultaneous depletion of dopamine- and serotonin-induced reductions in both PPI and P50 suppression providing evidence that both serotonin and dopamine may act synergistically to modulate sensorimotor and sensory gating. These findings, together with the findings discussed above for selective serotonin and dopamine depletion could be interpreted in many ways. First, it is possible that both serotonin and dopamine may modulate both PPI and P50, but independently they require significant perturbation of each system to affect gating. Hence, factors discussed previously such as dose, potency, and an inverted U relationship may all play a significant role in the likelihood of changes to gating occurring when targeted selectively. Second, it is possible that when targeted simultaneously, there may be a synergistic interaction between the serotonin and dopamine systems such that more robust and more consistent effects on gating are observed. Such effects on PPI and P50 suppression have been noted with regard to the noradrenergic system and its interaction with the serotonin system. Inconsistent effects of selective augmentation of noradrenaline (with noradrenaline reuptake inhibitors) on PPI have been reported with no effects with reboxetine (Phillips et al, $2000 \mathrm{~b})$ and a reduction with the more potent desipramine (Oranje et al, 2004), whereas simultaneously augmenting serotonin and noradrenaline with imipramine (a tricyclic antidepressant drug that inhibits both serotonin and noradrenaline reuptake) impaired both PPI and P50 suppression (Hammer et al, 2007).

The reductions in both PPI and P50 suppression with simultaneous serotonin and dopamine depletion may be important for our understanding of the neurochemical basis of sensorimotor and sensory gating deficits in schizophrenia. Our finding, together with evidence that the PPI and P50 suppression reductions in patients with schizophrenia may be normalized with atypical antipsychotics, which target both serotonin and dopamine neurotransmission (ie by inhibiting dopamine $\mathrm{D}_{2}$ receptors and $5-\mathrm{HT}_{2}$ receptors) (Hamm et al, 2001; Kumari and Sharma, 2002; Kumari et al, 2007; Light et al, 2000), suggests that dysfunction in both serotonin and dopamine neurotransmission may in part contribute to the disruption in sensorimotor and sensory gating observed in schizophrenia.

Although PPI and P50 suppression are both measures of gating, they are not correlated (Braff et al, 2007; Brenner et al, 2004; Oranje et al, 2006) and thus it has been suggested that they may not share the same neural mechanisms (Braff et al, 2007; Brenner et al, 2004). It is also possible then that there may be differential modulation of sensorimotor and sensory gating by various neurochemical systems (Braff et al, 2007). In our study, there was some evidence for differential effects of serotonin and dopamine on sensory $v s$ sensorimotor gating, as selective depletion of serotonin had no effects on P50 suppression but disrupted PPI. However, our findings of reductions in both PPI and P50 suppression with simultaneous depletion of both serotonin and dopamine suggest that both sensorimotor and sensory gating may be modulated by similar neurochemical systems and these systems may work synergistically. This 
supports the suggestion that while PPI and P50 do not share the same neural networks, they may share overlapping networks (Oranje et al, 2006) and hence it is possible that both serotonin and dopamine's modulation of PPI and P50 may be similar within critical areas of the overlapping network. These findings in general support observations in animals with equivalent measures on the neurochemical regulation of sensorimotor and sensory gating (Swerdlow et al, 2006).

There are some important methodological issues that require discussion here. First, the current study was conducted in males only. There is some evidence that the PPI levels are lower in females than in males (Swerdlow et al, 1993) and the 'female' sex steroid, estrogen, has been shown to attenuate PPI deficits (Gogos et al, 2006). Hence these findings cannot be extended to females. Second, given that we postulate the lack of effect of dopamine depletion on PPI and P50 suppression in the current study to be due to insufficient depletion of dopamine, it would be of interest to replicate this study using a pharmacological probe that can decrease dopaminergic function to a greater extent (ie $\alpha$ methyl-para-tyrosine). It is also worth noting here that the lack of effects observed after ATPD, and lack of change in PPI after ATD, cannot be explained by lack of power. Our study was adequately powered to detect a moderate effect size. The nonsignificant results all had a very small effect size (partial $\eta^{2}$ was 0.2 and $0.013-0.18$ for PPI and P50, respectively), suggesting that the effects were too small to be of physiological relevance. Finally, the findings of the current study are following acute pharmacological manipulation of the dopamine and serotonin systems in humans. The consequences of chronic dopamine and serotonin manipulation on PPI and P50 in humans require further investigation.

In summary, the current study investigated the effects of selective and simultaneous serotonin and dopamine depletion on PPI and P50 suppression measures of sensorimotor gating. The findings provide evidence for neurochemical differentiation with regard to the effects of serotonergic and dopaminergic modulation on PPI and P50 suppression. Selective depletion of dopamine had no significant effect on either PPI or P50 suppression, whereas selective serotonin depletion significantly disrupted PPI, but not P50 suppression. Finally, the simultaneous depletion of both dopamine and serotonin resulted in significant reductions in both PPI and P50 suppression. We suggest that these results can be explained by theories relating to optimal levels of neurotransmission and synergistic interactions between monoaminergic systems for normal 'gating' function. These findings suggest that a dysfunction in both serotonin and dopamine neurotransmission (eg disruption of optimal neurotransmission leading to dopaminergic hyperactivity in striatum or dopaminergic underactivity in cortex) may in part be responsible for the gating deficits observed in schizophrenia and that the effects of atypical antipsychotic drugs on sensorimotor gating and sensory gating may be related to normalization of optimal neurotransmission (ie reducing striatal dopaminergic hyperactivity and enhancing cortical dopaminergic underactivity). The recent evidence that atypical antipsychotic drugs including risperidone and olanzepine activate areas including the striatum and frontal cortex during PPI (Kumari et al, 2007) supports such a possibility.

\section{ACKNOWLEDGEMENTS}

This paper is dedicated to our colleague, friend, and $\mathrm{PhD}$ student Alan Dunne who tragically passed away during the study. He will be sadly missed by all. We thank Dr Susan Ilic for performing medicals on the study participants and for being on call during the study. Biochemical assays were performed by Dr Bernie McInerney under the auspices of the Australian Proteome Analysis Facility established under the Australian Government's Major National Research Facilities program. Fellowship support for Professor Pradeep Nathan was provided by the National Health and Medical Research Council (NHMRC) of Australia (ID no. 345709).

\section{DISCLOSURE OF CONFLICT OF INTEREST}

None of the authors have any financial interests to disclose.

\section{REFERENCES}

Abduljawad KA, Langley RW, Bradshaw CM, Szabadi E (1998). Effects of bromocriptine and haloperidol on prepulse inhibition of the acoustic startle response in man. J Psychopharmacol 12: 239-245.

Abduljawad KA, Langley RW, Bradshaw CM, Szabadi E (1999). Effects of bromocriptine and haloperidol on prepulse inhibition of the acoustic startle resposne in man. J Psychopharmacol 12: 239-245.

Abel KM, Allin M, van Amelsvoort T, Hemsley D, Geyer MA (2007). The indirect serotonergic agonist d-fenfluramine and prepulse inhibition in healthy men. Neuropharmacology 52: 1088-1094.

Adler LE, Cawthra E, Donovan KA, Harris JG, Nagamoto HT, Olincy A et al (2005). Improved P50 auditory gating with odansetron in medicated schizophrenia patients. Am J Psychiat 162: 386-388.

Adler LE, Freedman R, Ross RG, Olincy A, Waldo MC (1999). Elementary phenotypes in neurobiological and genetic study of schizophrenia. Biol Psychiatry 46: 8-18.

Adler LE, Hoffer LJ, Griffith J, Waldo MC, Freedman R (1992). Normalization by nicotine of deficient auditory sensory gating in the relatives of schizophrenics. Biol Psychiatry 32: 607-616.

Adler LE, Olincy A, Cawthra EM, McRae KA, Harris JG, Nagamoto HT et al (2004). Varied effects of atypical neuroleptics on P50 auditory gating in schizophrenia patients. Am J Psychiatry 161: 1822-1828.

Adler LE, Pachtman E, Franks RD, Pecevich M, Waldo MC (1982). Neurophysiological evidence for a defect in neuronal mechansims involved in sensory gating in schizophrenia. Biol Psychiatry 17: 639-654.

Adler LE, Rose GM, Freedman R (1986). Neurophysiologic studies of sensory gating in rats: effects of amphetamine, phencyclidine and haloperidol. Biol Psychiatry 21: 787-798.

Anokhin AP, Heath AC, Myers E, Ralano A, Wood S (2003). Genetic influences on prepulse inhibition of startle reflex in humans. Neurosci Lett 353: 45-48.

Arnsten AF, Goldman-Rakic PS (1998). Noise stress impairs prefrontal cortical cognitive function in monkeys: evidence for hyperdopaminergic mechanism. Arch Gen Psychiatry 55: 362-368.

Balaban MT, Losito BDG, Simons RF, Graham FK (1986). Off-line latency and amplitude scoring of the human reflex eye blink with Fortran IV. Psychophysiology 23: 612.

Becker J, Gomes I, Ghisolfi ES, Schuch A, Ramos FL, Ehlers JA et al (2004). Clozapine, but not typical antipsychotics, correct P50 
suppression deficit in patients with schizophrenia. Clin Neurophysiol 115: 396-401.

Bitsios P, Giakoumaki SG, Frangou S (2005). The effects of dopamine agonists on prepulse inhibition in healthy men depend on baseline PPI values. Psychopharmacology 182: $144-152$.

Bond A, Lader M (1974). The use of analog scales in rating subjective feelings. Br J Med Psychol 47: 211-218.

Boutros NN, Zouridakis G, Overall J (1991). Replication and extension of P50 findings in schizophrenia. Clin Electroencephalogr 22: 40-45.

Braff DL (1993). Information processing and attention dysfunctions in schizophrenia. Schizophr Bull 18: 233-259.

Braff DL, Geyer M (1990). Sensorimotor gating and schizophrenia: human and animal model studies. Arch Gen Psychiatry 47: 181-188.

Braff DL, Geyer MA, Swerdlow NR (2001). Human studies of prepulse inhibition of startle: normal subjects, patient groups and pharmacological studies. Psychopharmacology 156: 234-258.

Braff DL, Light GA, Swerdlow NR (2007). Prepulse inhibition and P50 suppression are both deficient but not correlated in schizophrenia patients. Biol Psychiatry 61: 1204-1207.

Brenner CA, Edwards CR, Carroll CA, Kieffaber PD, Hetrick WP (2004). P50 and acoustic startle gating are not related in healthy participants. Psychophysiology 41: 702-708.

Cadenhead KS, Braff DL (1999). Schizophrenia spectrum disorders. In: Dawson ME, Schell AM, Bohmelt AH (eds). Startle Modification: Implications for Neuroscience, Cognitive Science, and Clinical Science. Cambridge University Press: USA. pp 231-244.

Carpenter LL, Anderson GM, Pelton GH, Gaudin JA, Kirwin PDS, Price LH et al (1998). Tryptophan depletion during continuous CSF sampling in healthy human subjects. Neuropsychopharmacology 19: 26-35.

Clementz BA, Geyer MA, Braff DL (1998). Multiple site evaluation of P50 suppression among schizophrenia and normal comparison subjects. Schizophr Res 30: 71-80.

Cohen SA (2001). Amino acid analysis using precolumn derivatisation with 6-aminoquino lyl- $N$-hydroxysuccinimidyl carbamate. In: Cooper C, Packer N, Williams K (eds). Methods in Molecular Biology. Humana Press: New Jersey. pp 39-47.

Croft RJ, Dimoska A, Gonsalvez CJ, Clarke AR (2004). Suppression of P50 evoked potential component, schizotypal beliefs and smoking. Psychiatry Res 128: 53-62.

Dean B (2003). The cortical serotonin 2A receptor and the pathology of schizophrenia: a likely accomplice. J Neurochem 85 : $1-13$.

Della Casa V, Hofer I, Weiner I, Feldon J (1998). The effects of smoking on acoustic prepulse inhibition in healthy men and women. Psychopharmacology 137: 362-368.

Ellis KA, Mehta MA, Naga Venkatesha Murthy PJ, McTavish SF, Nathan PJ, Grasby PM (2007). Tyrosine depletion alters cortical and limbic blood flow but does not modulate spatial working memory performance or task-related blood flow in humans. Hum Brain Mapp [e-pub ahead of print].

Freedman R, Coon H, Myles-Worsley M, Orr-Urtreger A, Olincy A, Davis A et al (1997). Linkage of a neurophysiological deficit in schizophrenia to a chromosome 15 locus. Proc Natl Acad Sci USA 94: 587-592.

Geyer MA, Krebs-Thomson K, Braff DL, Swerdlow NR (2001). Pharmacological studies of prepulse inhibition models of sensorimotor gating deficits in schizophrenia: a decade in review. Psychopharmacology 156: 117-154.

Giakoumaki SG, Roussos P, Frangou S, Bitsios P (2007). Disruption of prepulse inhibition of the startle reflex by the preferential $\mathrm{D}(3)$ agonist ropinirole in healthy males. Psychopharmacology [e-pub ahead of print].
Gogos A, Nathan PJ, Guille V, Croft RJ, van den Buuse M (2006). Estrogen prevents 5-HT1A receptor-induced disruptions of prepulse inhibition in healthy women. Neuropsychopharmacology 31: 885-889.

Goldman-Rakic PS (1995). Cellular basis of working memory. Neuron 14: 477-485.

Gouzoulis-Mayfrank E, Heekeren K, Thelen B, Lindenblatt H, Kovar KA, Sass H et al (1998). Effects of the hallucinogen psilocybin on habituation and prepulse inhibition of the startle reflex in humans. Behav Pharmacol 9: 561-566.

Graham F (1975). The more or less startling effects of weak prestimulation. Psychophysiology 12: 238-248.

Graham SJ, Langley RW, Bradshaw CM, Szabadi E (2002). Effects of haloperidol and clozapine on prepulse inhibition of the acoustic startle response and the N1/P2 auditory evoked potential in man. J Psychopharmacol 15: 243-250.

Hamm A, Weike A, Schupp H (2001). The effect of neuroleptic medication on prepulse inhibition in schizophrenia patients: current status and future issues. Psychopharmacology 156: 259-265.

Hammer TB, Oranje B, Glenthoj BY (2007). The effects of imipramine on P50 suppression, prepulse inhibition and habituation of the startle response in humans. Int J Neuropsychopharmacol (in press).

Harmer C, McTavish S, Clark L, Goodwin G, Cowen P (2001). Tyrosine depletion attenuates dopamine function in healthy volunteers. Psychopharmacology 133: 329-342.

Harrison BJ, Olver JS, Norman TR, Burrows GD, Wesnes KA, Nathan PJ (2004). Selective effects of acute serotonin and catecholamine depletion on memory in healthy women. $J$ Psychopharmacol 18: 32-40.

Hashimoto K, Iyo M, Freedman R, Stevens KE (2005). Tropisetron improves deficient inhibitory auditory processing in DBA/2 mice: role of alpha 7 nicotinic acetylcholine receptors. Psychopharmacology 183: 13-19.

Hoffman HS, Fleshler M (1963). Startle reaction: modification by background acoustic stimulation. Science 141: 928-930.

Hutchison KE, Swift R (1999). Effect of d-amphetamine on prepulse inhibition of the startle reflex in humans. Psychopharmacology 143: 394-400.

Ison JR, McAdam DW, Hammond GR (1973). Latency and amplitude changes in the acoutic startle reflex produced by variations in auditory prestimulation. Physiol Behav 10: 1035-1039.

Jaskiw GE, Bongiovanni R (2004). Brain tyrosine depletion attenuates haloperidol-induced striatal dopamine release in vivo and augments haloperidol-induced catelepsy in rats. Psychopharmacology 172: 100-107.

Jensen KS, Oranje B, Wienberg M, Glenthoj BY (2007). The effects of increased central serotonergic activity on prepulse inhibition and habituation of the human startle response. Neuropsychopharmacology (in press).

Kedzior KK, Martin-Iverson MT (2007). Attention-dependent reduction in prepulse inhibition of the startle reflex in cannabis users and schizophrenia patients - a pilot study. Eur J Pharmacology 560: 176-182.

Koike K, Hashimoto K, Takai N, Shimizu E, Komatsu N, Watanabe $\mathrm{H}$ et al (2005). Tropisetron improves deficits in auditory P50 suppression in schizophrenia. Schizophr Res 76: 67-72.

Kumari V, Antonova E, Geyer MA, Ffytche D, Williams SC, Sharma T (2007). A fMRI investigation of startle gating deficits in schizophrenia patients treated with typical or atypical antipsychotics. Int J Neuropsychopharmacol 10: 463-477.

Kumari V, Mulligan OF, Cotter PA, Poon L, Toone BK, Checkley SA et al (1998). Effects of single oral administrations of haloperidol and d-amphetamine on prepulse inhibition of the acoustic startle reflex in healthy male volunteers. Behav Pharmacol 9: 567-576. 
Kumari V, Sharma T (2002). Effects of typical and atypical antipsychotics on prepulse inhibition in schizophrenia: a critical evaluation of current evidence and directions for future research. Psychopharmacology 162: 97-101.

Landis C, Hunt WA (1939). The Startle Pattern. Farrar and Rinehart: New York.

Laruelle M, Kegeles LS, Abi-Dargham A (2003). Glutamate, dopamine, and schizophrenia: from pathophysiology to treatment. Ann N Y Acad Sci 1003: 138-158.

Leyton M, Young SN, Pihl RO, Etezadi S, Lauze C, Blier P, et al (2000). Effects on mood of acute phenylalanine/tyrosine depletion in healthy women. Neuropsychopharmacology 52: 121-217.

Liechti ME, Geyer MA, Hell D, Vollenweider FX (2001). Effects of MDMA (ecstasy) on prepulse inhibition and habituation of startle in humans after pretreatment with citalopram, haloperidol, or ketanserin. Neuropsychopharmacology 24: 240-252.

Light GA, Geyer M, Clementz BA, Cadenhead K, Braff D (2000). Normal P50 suppression in schizophrenia patients treated with atypical antipsychotic medications. Am J Psychiatry 175: 767-771.

Light GA, Malaspina D, Geyer M, Luber BM, Coleman EA, Sackeim HA et al (1999). Amphetamine disrupts P50 suppression in normal subjects. Biol Psychiatry 49: 990-996.

Lu BY, Martin KE, Edgar JC, Smith AK, Lewis SF, Escamilla MA et al (2007). Effect of catechol $O$-methyltransferase $\mathrm{Val}(158) \mathrm{Met}$ polymorphism on the P50 gating endophenotype in schizophrenia. Biol Psychiatry [e-pub ahead of print].

Martin-Iverson MT, Else D (2000). PHNO, a selective dopamine D2 receptor agonist, does not reduce prepulse inhibition of the startle reflex in rats. Psychopharmacology 151: 38-48.

Matrenza C, Hughes J, Kemp AH, Wesnes K, Harrison BJ, Nathan PJ (2004). Simultaneous depletion of serotonin and catecholamines impairs sustained attention without affecting learning and memory in humans. J Psychopharmacol 18: 21-31.

McGhie A, Chapman J (1961). Disorders of attention and perception in early schizophrenia. Br J Med Psychol 34: 103-116.

McTavish SF, Callado L, Cowen PJ, Sharp T (1999b). Comparison of the effects of $\alpha$-methyl-p-tyrosine and a tyrosine-free amino acid load on extracellular noradrenaline in the rat hippocampus in vivo. J Psychopharmacol (Oxf) 13: 379-384.

McTavish SF, Cowen PJ, Sharp T (1999a). The effect of a tyrosinefree amino acid mixture on regional brain catecholamine synthesis and release. Psychopharmacology (Berl) 141: 182-188.

McTavish SF, McPerhson MH, Harmer CJ, Clark L, Sharp T, Goodwin GM et al (2001a). Antidopaminergic effects of dietary tyrosine depletion in healthy subjects and patients with manic illness. Br J Psychiatry 179: 356-360.

McTavish SF, Raumann B, Cowen PJ, Sharp T (2001b). Tyrosine depletion attenuates the behavioural stimulant effects of amphetamine and cocaine in rats. Eur J Pharmacol 424: 115-119.

Mehta MA, Gumaste D, Montgomery AJ, McTavish SF, Grasby PM (2005). The effects of acute tyrosine and phenylalanine depletion on spatial working memory and planning in healthy volunteers are predicted by changes in striatal dopamine levels. Psychopharmacology (Berlin) 26: 56-68.

Moja E, Stoff D, Gessa G, Castoldi D, Assereto R, Tofanetti O (1988). Decrease in plasma tryptophan after tryptophan-free amino acid mixtures in man. Life Sci 42: 1551-1556.

Montgomery AJ, McTavish SF, Cowen PJ, Grasby PM (2003). Reduction in brain dopamine concentration with dietary tyrosine plus phenylalanine depletion: a raclopride PET study. Am J Psychiatry 10: 1887-1889.

Moxon KA, Gerhardt G, Adler LE (2003a). Dopaminergic modulation of the P50 auditory-evoded potential in a computer model of the CA3 region of the hippocampus: its relationship to sensory gating in schizophrenia. Biol Cybern 88: 265-275.

Moxon KA, Gerhardt GA, Gulinello M, Adler LE (2003b). Inhibitory control of sensory gating in a computer model of the CA3 region of the hippocampus. Biol Cybern 88: 247-264.
Nagamoto HT, Adler LE, Hea RA, Griffith JM, McRae KA, Freedman R (1996). Gating of auditory P50 in schizophrenics: unique effects of clozapine. Biol Psychiatry 40: 181-188.

Nagamoto HT, Adler LE, McRae KA, Huettl P, Cawthra E, Gerhardt $\mathrm{G}$ et al (1999). Auditory P50 in schizophrenics on clozapine: improved gating parallels clinical improvement and changes in plasma 3-methoxy-4-hydroxyphenylglycol. Neuropsychobiology 39: $10-17$.

Nagamoto HT, Adler LE, Waldo MC, Griffith J, Freedman R (1991). Gating of auditory response in schizophrenics and normal controls: effects of recording site and stimulation interval on the P50 wave. Schizophr Res 4: 31-40.

Nathan PJ, Hughes J, McInerney B, Harrison BJ (2004). Simultaneous depletion of tryptophan, tyrosine and phenylalanine as an experimental method to probe brain monoamine function in humans. Int J Neuropsychopharmacol 7: 171-176.

Nishizawa S, Benkelfat C, Young SN, Leyton M, Mzengeza S, De Montigny C et al (1997). Differences between males and females in rates of serotonin synthesis in human brain. Proc Natl Acad Sci USA 94: 5308-5313.

Oldendorf WH, Szabo J (1976). Amino acid assignment to one of three blood brain barrier amino acid carriers. Am J Physiol 230: 94-98.

Oranje B, Geyer MA, Bocker KBE, Kenemans JL, Verbaten MN (2006). Prepulse inhibition and P50 suppression: commonalities and dissociations. Psychiatry Res 143: 147-158.

Oranje B, Verbaten MN, Kemner C, Kahn RS (2004). Modulating sensorimotor gating in healthy volunteers: the effects of desipramine and haloperidol. Psychiatry Res 127: 195-205.

Palmour RM, Ervin FR, Baker GB, Young SN (1998). An amino acid mixture deficient in phenylalanine and tyrosine reduces cerebrospinal fluid catecholamine metabolites and alcohol consumption in vervet monkeys. Psychopharmacology 13: 1-7.

Phillips MA, Langley RW, Bradshaw CM, Szabadi E (2000b). The effects of some antidepressant drugs on prepulse inhibition of the acoustic startle (eyeblink) response and the N1/P2 auditory evoked response in man. J Psychopharmacol 14: 40-45.

Phillips MA, Oxtoby EK, Langley RW, Bradshaw CM, Szabadi E (2000a). Effects of acute tryptophan depletion on prepulse inhibition of the acoustic startle (eyeblink) response and the N1/P2 auditory evoked response in man. J Psychopharmacol 14: 258-265.

Prinssen EPM, Assie M, Wouter K, Kleven MS (2002). Depletion of 5-HT disrupts prepulse inhibition in rats: dependence on the magnitude of depletion, and reversal by a 5-HT precursor. Neuropsychopharmacology 26: 340-347.

Prosser CL, Hunter WS (1936). The extinction of startle responses and spinal reflexes in the white rat. Am J Physiol 117: 609-618.

Reilly JG, McTavish SF, Young AH (1997). Rapid depletion of plasma tryptophan: a review of studies and experimental methodology. J Psychopharmacol 11: 381-392.

Riba J, Rodriguez-Fornells A, Barbanoj MJ (2002). Effects of ayahuasca on sensory and sensorimotor gating in himans as measured by P50 suppression and prepulse inhibition of the startle reflex, respectively. Psychopharmacology 165: 18-28.

Sambeth A, Blokland A, Harmer CJ, Kilkens TO, Nathan PJ, Porter $\mathrm{RJ}$ et al (2007). Sex differences in the effect of acute tryptophan depletion on declarative episodic memory: a pooled analysis of nine studies. Neurosci Biobehav Rev 31: 516-529.

Schmitt JA, Jorissen B, Sobezak S, van Boxtel MPJ, Hogervorst E, Deutz NEP et al (2000). Tryptophan depletion impairs memory consolidation but improves focused attention in healthy young volunteers. J Psychopharmacol 14: 21-29.

Sobczak S, Riedel WJ, Booij I, Hen Rot MA, Deutz NEP, Honig A (2002). Cognition following acute tryptophan depletion: difference between first degree-degree relatives of bipolar disorder patients and matched healthy control volunteers. Psychol Med 32: 503-515. 
Swerdlow NR, Auerbach P, Monroe SM, Hartston H, Geyer MA, Braff DL (1993). Men are more inhibited than women by weak prepulses. Biol Psychiatry 34: 253-260.

Swerdlow NR, Braff D, Geyer M (2000). Animal models of deficient sensorimotor gating: what we know, what we think we know, and what we hope to know soon. Behav Pharmacol 11: 185-204.

Swerdlow NR, Eastvold A, Karban B, Ploum Y, Stephany N, Geyer MA et al (2002a). Dopamine agonist effects on startle and sensorimotor gating in normal male subjects: time course studies. Psychopharmacology 161: 189-201.

Swerdlow NR, Geyer MA, Shoemaker JM, Light GA, Braff DL, Stevens KE et al (2006). Convergence and divergence in the neurochemical regulation of prepulse inhibition of startle and N40 suppression in rats. Neuropsychopharmacology 31: 506-515.

Swerdlow NR, Hartman PL, Auerbach PP (1997). Changes in sensorimotor inhibition across the menstrual cycle: implications for neuropsychiatric disorders. Biol Psychiatry 41: 452-460.

Swerdlow NR, Platten A, Shoemaker J, Pitcher L, Auerbach PP (2001). Effects of pergolide on sensorimotor gating of the startle reflex in rats. Psychopharmacology 158: 230-240.

Swerdlow NR, Stephany N, Shoemaker JM, Ross L, Wasserman LC, Talledo J et al (2002b). Effects of amantadine and bromocriptine on startle and sensorimotor gating: parametric studies and cross-species comparisons. Psychopharmacology 164: 82-92.

Swerdlow NR, Shoemaker JM, Pitcher L, Platten A, Kuczenski R, Eleey CC et al (2002c). Genetic differences in startle gatingdisruptive effects of apomorphine: evidence for central mediation. Behav Neurosci 116: 682-690.
Vollenweider FX, Csomor PA, Knappe B, Geyer MA, Quednow BB (2007). The effects of the preferential 5-HT2A agonist psilocybin on prepulse inhibition of startle in healthy human volunteers depend on interstimulus interval. Neuropsychopharmacology 32: 1876-1887.

Vollenweider FX, Remensberger S, Hell D, Geyer MA (1999). Opposite effects of 3,4-methylenedioxymethamphetamine (MDMA) on sensorimotor gating in rats versus healthy humans. Psychopharmacology 143: 365-372.

Ward PB, HOffer LD, Liebert BJ, Catts SV, O'Donnell M, Adler LE (1996). Replication of a P50 auditory gating deficit in Australian patients with schizophrenia. Psychiatry Res 64: 121-135.

Weike AI, Bauer U, Hamm AO (2000). Effective neuroleptic medication removes prepulse inhibition deficits in schizophrenia patients. Biol Psychiatry 47: 61-70.

Williams GV, Goldman-Rakic PS (1995). Blockade of dopamine D1 receptors enhances memory fields of prefrontal neurons in primate cerebral cortex. Nature 376: 572-575.

Williams WA, Shoaf SE, Hommer D, Rawlings R, Linnoila M (1999). Effects of acute Tryptophan depletion on plasma and cerebrospinal fluid tryptophan and 5-hydroxyindoleacetic acid in normal volunteers. J Neurochem 72: 1641-1647.

Yee CM, White PM (2001). Experimental modification of P50 suppression. Psychophysiology 38: 531-539.

Young SN, Smith SE, Phil RO, Ervin FR (1985). Tryptophan depletion causes rapid lowering of mood in normal males. Psychopharmacology 87: 173-177. 